\title{
A New Gold Refining Facility
}

\author{
MODERNIZED AND EXPANDED COMPLEX FOR \\ A WIDE RANGE OF REFINABLE MATERIALS
}

\author{
F. T. Embleton \\ Johnson Matthey \& Co. Limited, London, U.K.
}

\begin{abstract}
An extensive programme of modernization of Johnson Matthey's refineries now provides them with the largest capacity world-wide for the evaluation and efficient processing of a great variety of materials containing gold and other precious metals.
\end{abstract}

\begin{abstract}
Major improvements and extensions to the existing plant, taking two years to complete, have now provided Johnson Matthey Chemicals Limited, the company controlling the group's refining and chemical operations in the United Kingdom, with the most modern and best equipped refinery in the world, with the largest capacity for evaluating and processing every type of both primary and secondary refinable material. The feed material includes gold and silver bullion, demonetised coinage, scrap and waste material from the electronics, chemical, electroplating and jewellery manufacturing industries, as well as products from the mining sector, such as doré bars, alluvial gold and gold-containing copper refinery tank house slimes.

The new plant, situated at Brimsdown, near Enfield, England, was designed to ensure the maximum return from all forms of input material. To this end, particular attention was paid to the security of materials received from clients, to accurate weighing, sampling and analysis, and to the highest possible recovery of values during the refining processes.
\end{abstract}

\section{Sampling and Analysis}

With the present high intrinsic values of gold and silver, the accurate evaluation of feed material containing these metals has reached a new level of importance. Two basic routes are involved in this preliminary operation. Metallic materials, such as bullion and coin, are first melted in a bank of nine induction furnaces having capacities ranging from 4 to $500 \mathrm{~kg}$. The furnaces are equipped with fume extraction hoods and bag filters, the dust from which is collected for recycling. Induction furnaces were chosen because of their speed of melting, the high temperatures that are attainable in them and the vigorous stirring action which the electromagnetic field imparts to the melt, thus assisting in homogenization and truly representative sampling.
Materials such as industrial and jewellers' scrap and sweepings or other heterogeneous types of input are first burnt in gas-fired incinerators to eliminate their organic contents, ground to ensure uniform particle size, and then screened for blending and subsequent sampling. Two 1 tonne orbital screw blenders are installed and these discharge into containers which are lifted to the top of a specially designed twin-stream sampling train, which draws two samples each constituting 10 per cent of the total charge. Each of the samples is then fed to another sampler which takes a further 10 per cent cut. The two resulting 1 per cent samples, taken for comparison and typically weighing about $10 \mathrm{~kg}$ each, are passed to the final sampling room for further size reduction. Each piece of equipment in the grinding, blending and sampling areas is fitted with its own dust control unit to ensure that any airborne material is collected and restored to the particular client's batch of material.

The final sample for analysis is reduced to $2 \mathrm{~kg}$ on a rotary riffle and then ground to a particle size of less than $0.12 \mathrm{~mm}$ in a vibratory mill. Any remaining metallic material is melted for analysis, the powder being further reduced in volume on a small rotary riffle, to provide sufficient samples of $100 \mathrm{~g}$ each.

In addition to the traditional methods of fire assay and gravimetric chemical analysis, a wide range of techniques is available in the new laboratories. These include atomic absorption, X-ray fluorescence, as well as inductively coupled plasma spectroscopy. The latter technique uses a computer-controlled direct reading emission spectrograph with a radio frequency argon plasma source unit. The analytical results are fed into the stock-control computer and then reported to the client.

\section{Smelting in the Blast Furnace}

The smelting of secondary materials takes place in a new blast furnace that was specially designed and 

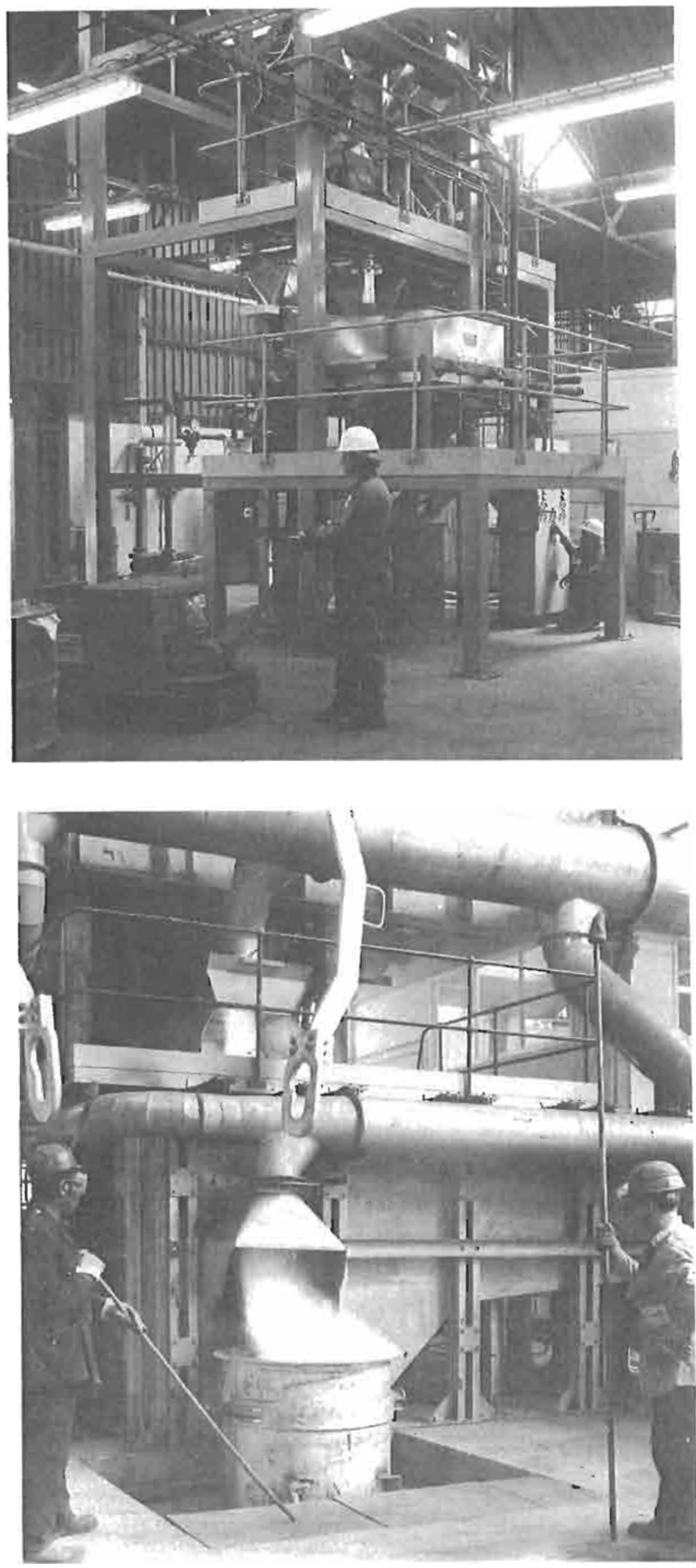

The blended scrap and waste material is fed to a twin-stream Knight sampling train which produces two 1 per cent samples for analysis
The specially designed blast furnace. The molten product is tapped into the forehearth and settles into three phases, a slag, a copper matte of linailed precious metal content and a lead bullion containing the unajor part of the gold and silver 
built to the company's specifications. It incorporates a number of novel features aimed at achieving optimum recovery of the precious metals at the lowest possible cost. Extensive use is made of microprocessors to ensure ideal blending of all the input materials and to control the smelting reactions. The furnace has a hearth area of $2.1 \mathrm{~m}^{2}$ and is over $4 \mathrm{~m}$ in height to charge level. It is charged by an inclined belt conveyor which in turn is fed from fourteen hoppers, controlled by a micro-processor.

The pay-load materials are first blended with the necessary additions of flux and then fed to a disc pelletizer for conversion into nodules. These are smelted with coke, litharge (lead oxide), iron pyrites and slag from the reverberatory furnace. Oxygenenriched air is blown through sixteen tuyères in the lower part of the furnace, and as the charge descends the litharge is reduced to lead which collects the gold and silver, while the pyrites decomposes to form ferrous sulphide and sulphur, the latter element in turn converting any copper that may be present into a matte. The complete molten charge is tapped into the forehearth, which is so designed that the three phases which are produced and separate according to their density can be tapped individually.

The molten slag flows continuously from the top of the settler into a continuous casting machine. After analysis to ensure that it contains no values, it is disposed of or dumped.

The second phase, the copper matte, containing gold and silver, is cast on a second casting machine, crushed, ground and then roasted to copper oxide in a six-hearth Herreshoff-type furnace. The resulting roasted matte is leached with dilute sulphuric acid to remove the copper, which is then recovered electrolytically. The residue is smelted in a rotary reverberatory furnace to yield a rich lead bullion.

The original lead bullion, recovered from the blast furnace and containing most of the gold and silver, is fed to a cupellation furnace, where the lead is oxidized to litharge which is run off and recycled, leaving silver-containing gold incorporating small quantities of the platinum group metals. This melt is cast into anodes for electrolytic refining, in which process the gold remains as a slime in the anode bags.

A new computer-controlled facility for the treatment of gold-bearing copper refinery slimes has been installed. The plant makes provision for the recovery of selenium, and additionally yields copper for subsequent electrolytic refining and a residue containing gold, silver and lead which then joins the main smelting stream for recovery.

\section{Gold Refining}

Metallic material of less than 20 weight per cent gold content is fed into the cupellation furnace used

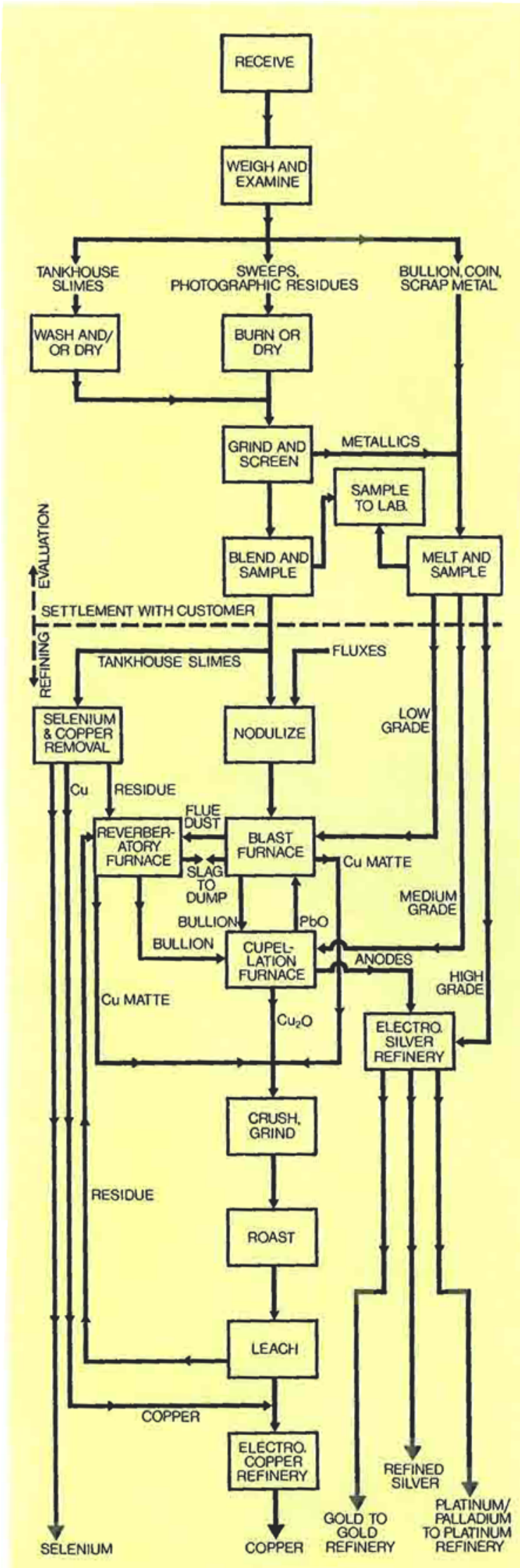

Flowchart of the refinery complex 


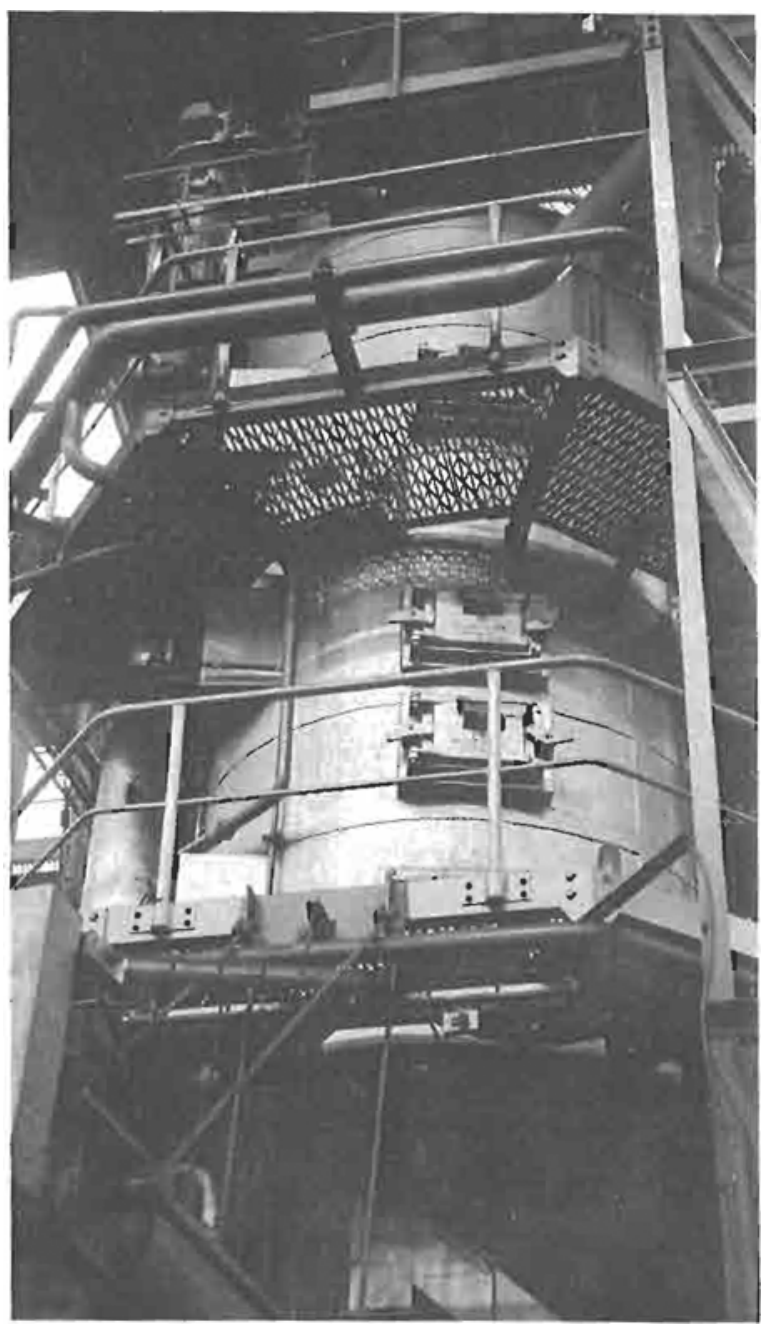

The copper matte from the blast funace, after crushing and grinding, is roasted in a six-liearth Herreshoff-type furmace illustrated here

for refining the lead bullion, as discussed earlier. Richer material is refined by the Miller chlorine process. This, the most widely used of all gold refining methods, depends upon the fact that molten gold is virtually inert to chlorine, while most base metals react with it to form molten or volatile chlorides. The crude gold feed, together with high grade scrap and material from earlier stages of refining, is melted in clay-lined graphite crucibles into the bottom of which chlorine is blown through clay pipes and allowed to pass through the melt.

At the end of the reaction, the surface is cleaned up by the addition of a flux and the gold is transferred to a large tilting furnace for final casting of a uniform product. The quality that is obtained is normally 99.6 weight per cent gold, the standard for 'good delivery' bars on the world bullion markets. This degree of purity is, however, not acceptable for many industrial applications in which very low levels of impurities must be maintained. The upgrading of the 99.6 per cent pure chlorine-refined gold is carried out electrolytically by the Wohlwill process, the impure material being cast into anodes and electrolyzed in a gold chloride/hydrochloric acid medium. Gold of 99.99 per cent purity is deposited onto titanium cathodes, from which it is collected, melted and cast into bars.

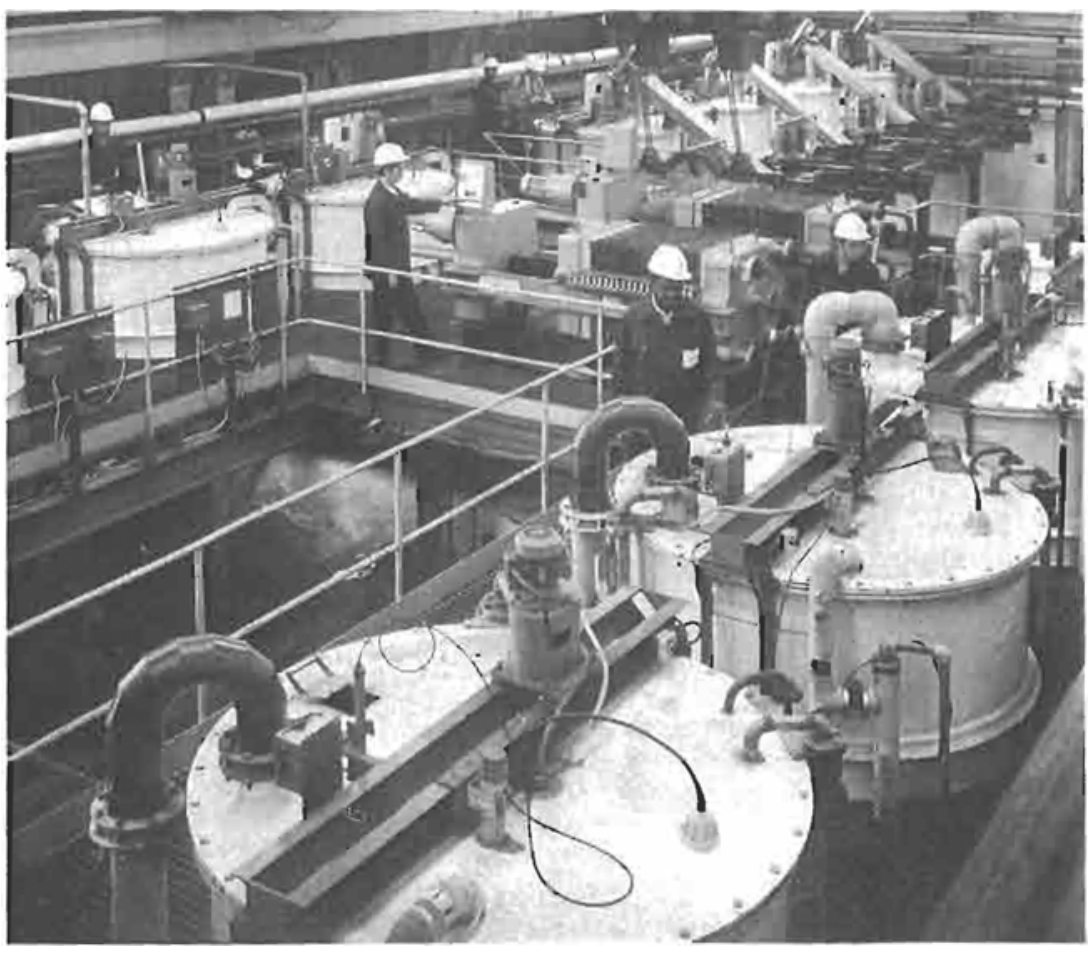

A new process for the treatment of gold-containing copper refinery tank house slines has been introduced to supplement the other refining circuits. This plant is automatically controlled by computer 